Article

\title{
An Emergency Decision-Making Method for Urban Rainstorm Water-Logging: A China Study
}

\author{
Jiyong Ding ${ }^{1,2, * \mathbb{C}}$, Juefang Cai ${ }^{1}$, Guangxiang Guo ${ }^{1,3}$ and Chen Chen ${ }^{1}$ \\ 1 Institute of Engineering Management, Hohai University, Nanjing 211100, China; jfcai@hhu.edu.cn (J.C.); \\ yyccjf@163.com (G.G.); 171312070003@hhu.edu.cn (C.C.) \\ 2 Jiangsu Provincial Collaborative Innovation Center of World Water Valley and Water Ecological Civilization, \\ Nanjing 211100, China \\ 3 Water Affairs Bureau of Guangzhou Municipality, Guangzhou 510000, China \\ * Correspondence: jyding@hhu.edu.cn; Tel.: +86-25-6851-4710
}

Received: 19 August 2018; Accepted: 26 September 2018; Published: 27 September 2018

check for updates

\begin{abstract}
With the rapid development of the urbanization process, rainstorm water-logging events occur more frequently in big cities in China, which causes great impact on urban traffic safety and brings about severe economic losses. Water-logging has become a hot issue of widespread concern in China. As one kind of natural disasters and emergencies, rainstorm water-logging has the uncertainties of occurrence, development, and evolution. Thus, the emergency decision-making in rainstorm water-logging should be carried out in stages according to its development trend, which is very complicated. In this paper, an emergency decision-making method was proposed for urban water-logging with a hybrid use of dynamic network game technology, Bayesian analysis, and multi-attribute utility theory. The dynamic game process between "rainstorm water-logging" and "decision-making group" was established and the dynamic generation of emergency schemes was analyzed based on Bayesian analysis in various stages of water-logging. In terms of decision-making attributes, this paper mainly considered two goals, i.e., ensuring smooth traffic and controlling emergency cost. The multi-attribute utility theory was used to select the final scheme. An example analysis in Guangzhou of China showed that the method is more targeted and can achieve emergency management objectives more effectively when compared with traditional methods. Therefore, it can provide reference for the scientific decision-making of emergency management in urban rainstorm water-logging.
\end{abstract}

Keywords: rainstorm water-logging; emergency decision-making; dynamic network game technology; Bayesian analysis; multi-attribute utility theory

\section{Introduction}

Due to the rapid development of the urbanization process, there have been frequent incidents of rainstorm water-logging around the world [1]. According to the data released by relevant UN departments, floods account for the first or second place in all disasters whether considering the number of people affected, the number of deaths, or the economic losses [2] especially in developing countries such as Bangladesh, India, Nepal, etc. [3]. China is one of the countries most affected by floods in the world [4]. The metropolises such as Beijing, Guangzhou, and Shanghai have frequently been flooded during the summer rains in recent years [5]. "Sea views in cities" has become synonymous with Chinese cities' suffering from rainstorm water-logging [6]. The loss of urban water-logging accounts for a considerable proportion of the total flood disaster losses in the country [7]. Frequent urban water-logging has severely restricted the stability of China's urban society and economic development [8]. 
Since the founding of the People's Republic of China, the development of water conservancy projects has been in full swing [9]. The flood control engineering system of China's large-scale rivers has been nearly completed. Thus, cities are less likely to be submerged due to the collapse of river dykes. However, the average annual damage caused by internal flooding is more serious than that of external flooding since the urban rainstorm water-logging breaks out suddenly with a short foreseeing period and the construction of urban drainage capacity is relatively lagging behind [10]. At present, even though the construction of public facilities is constantly improving, the rainstorm water-logging still brings tremendous pressure to the city's drainage system [11]. In addition, many cities in China are still busy constructing buildings and infrastructures especially subway projects in recent years, which results in the destruction of drainage networks [12]. This undoubtedly increased the incidence of urban water-logging. The sponge city has been vigorously promoted in recent years [13], but the annual rainstorm water-logging are still commonplace. Severe urban water-logging disasters may cause large-scale traffic and communication disruptions and billions of dollars in losses [14]. Taking the rainstorm water-logging that happened in Guangzhou City, capital of Guangdong Province, in 2010 as an example, with the specific geographical location shown in Figure 1, we can see the serious consequences of water-logging in China to a certain extent. According to the statistics of the Guangzhou Command Center for Flood, Drought and Typhoon Emergencies, 102 towns (sub-districts) in the city were flooded, 109 houses collapsed, more than 170 square kilometers of farmland were flooded, and the affected population was 32,166. Water-logging occurred in 118 locations in the central city of which 44 water-logging sites were very serious. Local traffic jams were caused and some temporary shops were flooded. The city's economic losses amounted to approximately $\$ 80$ million.

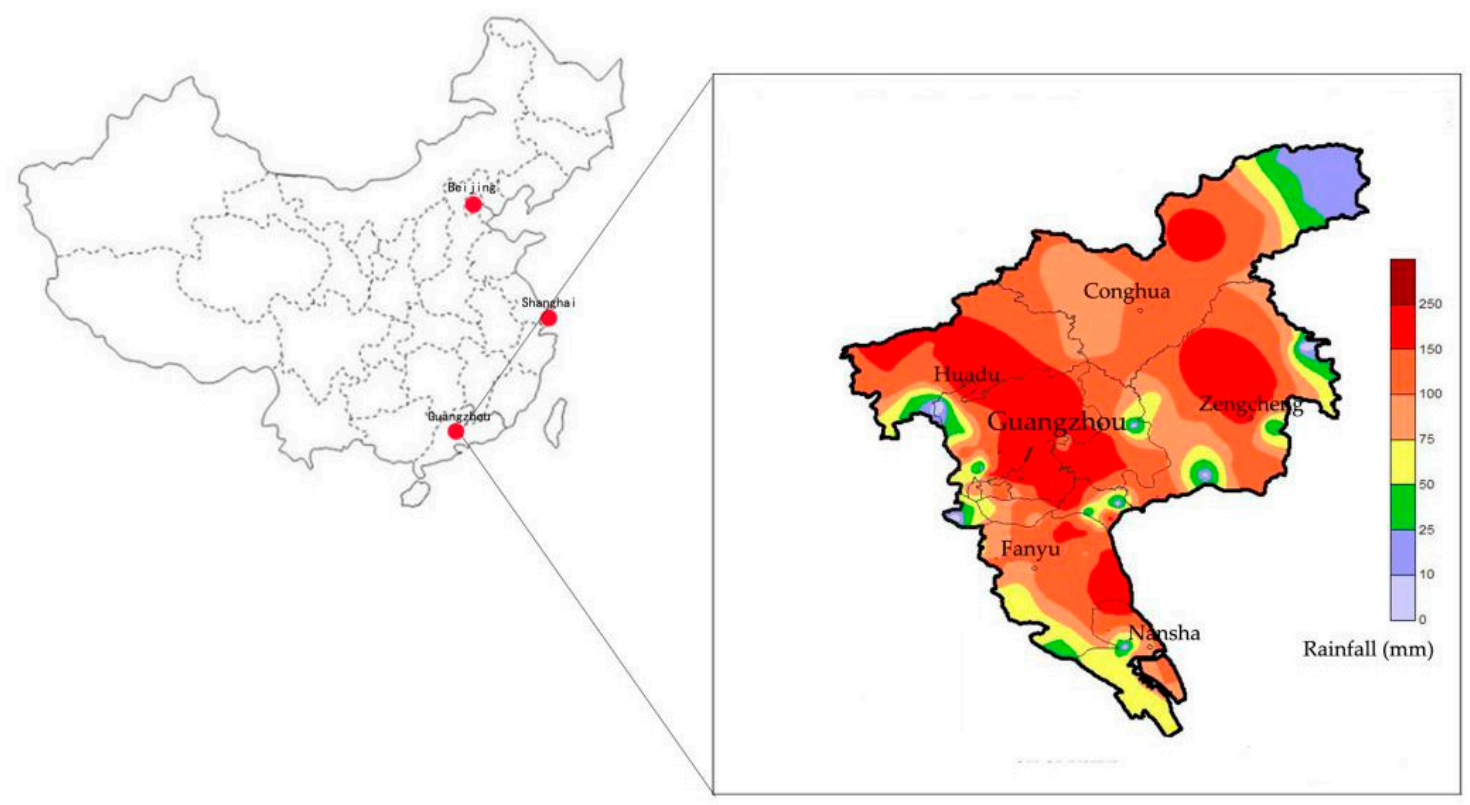

Figure 1. Rainfall distribution in different districts of Guangzhou in a water-logging event.

In the process of rapid urbanization, the population is highly concentrated in the city, the urban area is expanding rapidly, and the urban system functions are generally complicated [15], which has led to an increase in the threat posed by urban water-logging. Compared with natural factors, human factors are the main focus in the emergency management of water-logging such as an imperfect emergency linkage system (poor inter-departmental emergency coordination mechanism) and a low level of emergency management, etc. [16]. Therefore, it is urgent to strengthen the research on the emergency management of rainstorm water-logging. This paper focuses on the emergency decision-making problem of rainstorm water-logging and aims to propose an effective emergency decision-making method for urban water-logging disasters. As a typical city that seriously suffered 
from water-logging disasters in China, Guangzhou is taken as the real background to verify the effectiveness of the proposed method with some hypothetical data in this study. Figure 1 shows the distribution of rainfall in a certain water-logging event in Guangzhou.

\section{Literature Review}

At present, the research on urban rainstorm water-logging mainly focuses on cause analysis and control measures, disaster risk assessment, and early warning simulation.

Compared with natural disasters, the causes of water-logging involve more human factors including the increase of an urban impervious area [17], natural topographical constraints [18,19], imperfect municipal rainwater pipe network designing [20], and lack of communication and cooperation between relevant departments and majors [21]. The risk assessment method is more about the use of advanced technologies such as GIS (Geographic Information System) and remote sensing imagery, which aims to conduct a scenario analysis and a disaster risk assessment for water-logging disasters [22,23]. In the current research, the disaster risk assessment system is being studied further. Yin et al. [23] established a comprehensive disaster risk assessment model from three aspects including hazard factor assessment, vulnerability assessment, and exposure analysis. Cai et al. [24] proposed a risk assessment method in terms of risk assessment, emergency assessment, loss assessment, social impact assessment, and performance assessment, etc. The above research laid a good foundation for emergency management.

Nowadays, the new generation of IoT (Internet of Things) technology and GPRS (General Packet Radio Service) technology are used more and more to collect and process real-time data in urban areas in the early warning of rainstorm water-logging [25], which can improve the monitoring and the early warning system. Jiang et al. [26] drew componentized emergency plans based on a comprehensive integration platform, which realized the digitization, procedurization, visualization of urban emergency response plans, and made them more knowledgeable. Sun et al. [27] constructed a full-chain and multi-dimensional disaster scenario deduction scheme based on the flood model and multi-agent urban road condition model and assessed the emergency rescue scheme from the perspective of the damaged vehicles and people exposed security threats. This study provided a new idea and approach to emergency decision-making of water-logging.

In the process of emergency decision-making, the emergency plan is an important part of the emergency system, which is of great importance to make fast and effective responses and reduce the impact of the emergency [28,29]. Hoarda et al. [30] used the system dynamics to analyze the influencing factors of the emergency plan and developed the corresponding emergency plan by computer simulation of the emergency situation. This method laid a certain foundation for intelligent decision-making. With the research on emergency decision-making going forward, people gradually realized the dynamic characteristics of emergencies with continuous information changes. Yang et al. [31] proposed a sequential-based dynamic game model. By using this model, effective responses can be made according to the time sequence of the occurrence of various events and the continuous improvement of related information. Wang et al. [32] took the 2012 Beijing heavy rain as a case study and concluded that the social media text stream usually contains a large amount of timely information about the emergency. This information, if used properly, can help decision makers make different decisions. Yu et al. [33] designed a two-stage method for the typhoon disaster emergency scheme generation and adjustment considering the uncertainty of typhoon forecasting. At the first stage, case-based reasoning (CBR) is used to generate preliminary emergency plans and, at the second stage, the emergency plan is adjusted dynamically through prospect theory in which it is considered that individuals will have different risk attitudes based on different locations of reference points. Anderssonroswall et al. [34] believed that a systematic approach should be adopted to address the complex environmental and social risk management decisions resulting from flood hazard policies and proposed a comprehensive multi-criteria framework that includes simulation models, decision analysis tools, and a set of policy-making recommendations. Moreover, multi-attribute decision-making 
methods are also commonly used in emergency decision-making processes, which have been applied in many disciplines such as economics [35], military [36], industry [37], and logistics [38], etc. Chen et al. [39] considered that the uncertainty of information is the research focus in the field of emergency management and put forward a multi-attribute emergency decision-making method based on the relevance of information sources. Liu et al. [40] proposed a multi-attribute risk decision-making method for the response of emergencies when considering the fact that the multi-state evolution of emergencies would result in different outcomes.

In summary, it can be seen that the current research on emergency management decision-making was less common on specific types of events and it was even more rare for rainstorm water-logging. As one kind of emergencies, the characteristics and goals of rainstorm water-logging emergency decision-making are similar to that of other emergencies like a typhoon. Thus, related research in typhoons can provide references to the emergency management in water-logging. However, the water-logging has its own uniqueness, which calls for special studies on emergency decision-making. At present, some related work focused on the analysis and application of mathematical models in rainstorm water-logging rather than on the perspective of emergency management. There was less research on emergency management decisions and it lacked a systematic approach for emergency decision-making in water-logging. Moreover, most of the existing emergency decision-making methods were still single-stage processes that ignored the unique characteristics of water-logging. Among them, the most important is that the multi-stage evolution process of the water-logging state is influenced by previous decisions made by the decision-making group. Therefore, it is necessary to conduct research on an emergency decision-making method focusing on the multi-stage evolution process.

The aim of this paper is to develop a systematic emergency decision-making approach for urban rainstorm water-logging. The remaining parts of this paper are organized as follows. Section 3 focuses on the research methods. Section 4 presents an example that illustrates the applicability of these methods. Section 5 discusses the advantages and disadvantages of the methods. Section 6 provides the conclusions.

\section{Materials and Methods}

In this study, we have employed three major approaches, i.e., Dynamic Game Process Model, Bayesian Analysis, and Multi-Attribute Utility Theory to analyze the issue of urban water-logging as a multi-stage evolution process when considering the case of Guangzhou city.

\subsection{Study Area}

Guangzhou, the capital of Guangdong Province, is located at $113^{\circ} 17^{\prime}$ east longitude and $23^{\circ} 8^{\prime}$ north latitude. It is not only the third largest city in China and the largest city in southern China, but it is also a political, economic, technological, educational, and cultural center. Guangzhou has always been a city with plenty of rainfall and there are many more incidents of water-logging.

In Guangzhou, there are different degrees of water-logging in various districts during the rainstorm. According to the Guangzhou Rainstorm Water-logging Research Report [41], the causes of urban water-logging problem are quite complicated, which is shown in Figure 2. It can be seen that $48 \%$ of the water-logging in the central urban area are mainly caused by a lack of or a low standard of a drainage network. In addition, $17 \%$ occurs due to pipe network blockage, $15 \%$ results from low terrain, $9 \%$ takes place due to blocked rivers or backwater, and $7 \%$ is caused by construction effects. 


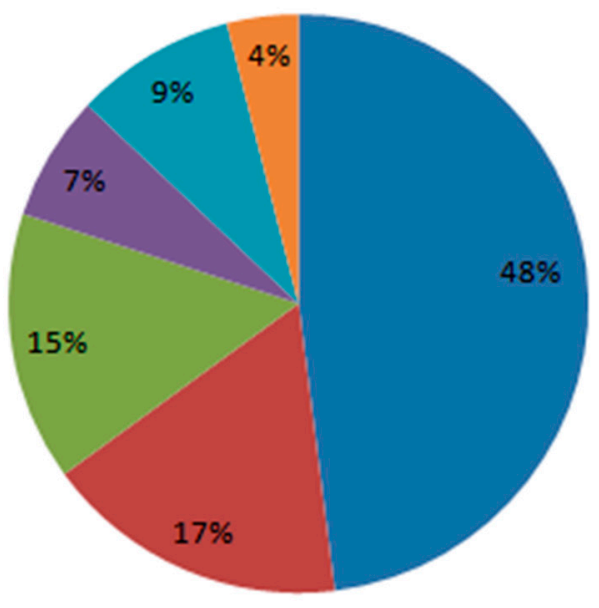

Drain pine network is lacking/Low standard

Low terrain

Pinenetwork blockage

Construction impcat

River

blocked/Backwater

Others

Figure 2. Main causes of water-logging in the downtown area of Guangzhou.

In order to effectively cope with the rainstorm water-logging, the Guangzhou government has classified the water-logging according to its severity. The levels of water-logging are shown in Table 1. Considering the regional and temporal elements of water-logging, the levels can be adjusted accordingly.

Table 1. Level classification of rainstorm water-logging in Guangzhou.

\begin{tabular}{cccc}
\hline Level & Meaning & Hazard Level & Preventive Measures \\
\hline Level III & $\begin{array}{c}\text { 30\% of the water-logging } \\
\text { sites reach a depth of } \\
15 \sim 30 \mathrm{~cm}\end{array}$ & $\begin{array}{c}\text { Mild water-logging, which will } \\
\text { not cause serious consequences. } \\
\text { Urban traffic will be partially } \\
\text { blocked and affect the normal } \\
\text { travel of citizens. }\end{array}$ & $\begin{array}{c}\text { Pedestrians should be advised } \\
\text { not to wade and not to pass } \\
\text { in principle. }\end{array}$ \\
\hline Level II & $\begin{array}{c}\text { 30\% of the water-logging } \\
\text { sites reach a depth of } \\
30 \sim 50 \mathrm{~cm}\end{array}$ & $\begin{array}{c}\text { Moderate water-logging, severe } \\
\text { drainage in areas with poor } \\
\text { drainage, large-scale urban } \\
\text { traffic is blocked, seriously } \\
\text { affecting citizens' travel. }\end{array}$ & $\begin{array}{c}\text { Measures should be taken as } \\
\text { soon as possible to reduce } \\
\text { water-logging and pedestrians } \\
\text { are prohibited from entering } \\
\text { severe areas. }\end{array}$ \\
\hline Level I & $\begin{array}{c}30 \% \text { of the water-logging } \\
\text { sites reach a depth of } \\
\text { more than } 50 \mathrm{~cm}\end{array}$ & $\begin{array}{c}\text { Severe water-logging, urban } \\
\text { traffic is rampant, seriously } \\
\text { affecting urban operations. }\end{array}$ & $\begin{array}{c}\text { Go out to fight against } \\
\text { disasters and rescue. Prohibit } \\
\text { pedestrians and vehicles from } \\
\text { passing through. }\end{array}$ \\
\hline
\end{tabular}

\subsection{Dynamic Game Process Model}

The emergency decision for rainstorm water-logging is dynamic since the state of water-logging in each phase is changing and it is necessary to make a phased or temporary decision. At each decision point, the decision-making group should make a choice based on the consequences or observed information from the previous-stage decision and the future information predicted at this time point. Specifically, the decision-making group should refer to two aspects of indicators in the emergency decision-making process, i.e., the current level of rainstorm water-logging and the predicted future weather information from a weather forecast. Based on these two aspects of information, decisions will be made regarding the level of the emergency scheme that should be adopted in the next stage.

The "rainstorm water-logging" and the "decision-making group" launched a game in several stages. The steps are shown in Figure 3. This game requires the "decision-making group" to grade the state of "rainstorm water-logging" beforehand. Assuming that there are $n$ states (levels) for the "rainstorm water-logging," the "decision-making group" should have a transcendental belief about the probability $\left(p_{i}\right)$ that the "rainstorm water-logging " is at the $i$-th state and the probability $\left(p_{i j}\right)$ of 
the water-logging's evolving from the $i$-th state to the $j$-th state, that is, the "decision-making group" should estimate the possible probability distributions of various states of rainstorm water-logging: $P_{i}=$ $\left(p_{1}, p_{2}, \ldots p_{n}\right)$ and the probability matrix $\left(p_{i j}\right)$ of mutual transitions between these states as follows.

$$
P_{i j}=\left\{\begin{array}{cccc}
p_{11} & p_{12} & \ldots & p_{1 n} \\
p_{21} & p_{22} & \ldots & p_{2 n} \\
\ldots & \ldots & \ldots & \ldots \\
p_{n 1} & p_{n 2} & \ldots & p_{n n}
\end{array}\right\}
$$

With the progress of the "game," the "decision-making group" uses Bayes' rule to dynamically correct these prior beliefs and then select the schemes for subsequent stages. The options for the "decision-making group" may be different at different stages. Figure 3 shows the game process between the "rainstorm water-logging" and the "decision-making group."

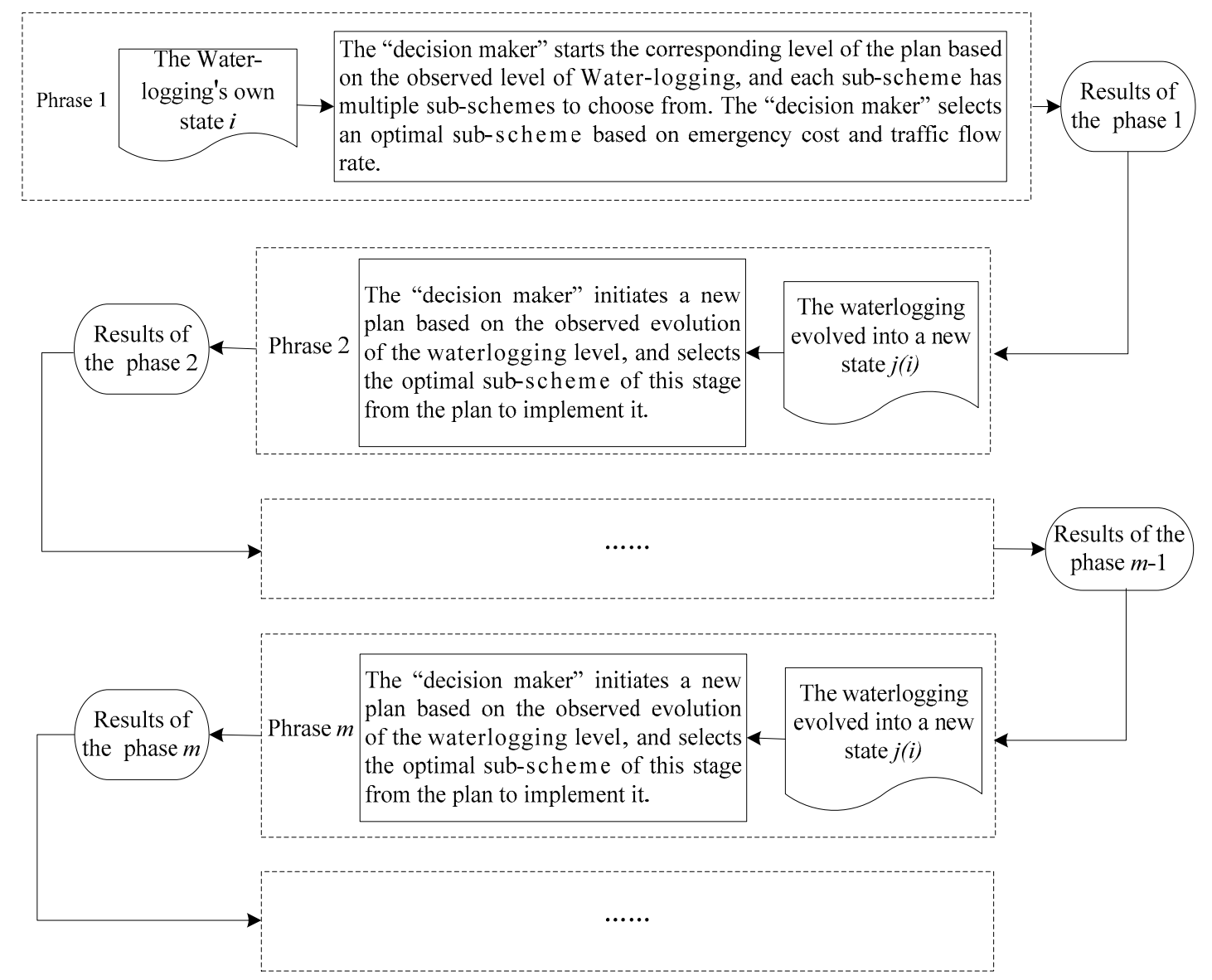

Figure 3. Steps of staged game between the "rainstorm water-logging" and the "decision-making group".

\subsection{Dynamic Generation of Emergency Schemes Based on Bayesian Analysis}

Without any information being known, the decision-making group has a natural understanding of the occurrence of rainstorm water-logging called the prior probability of rainstorm water-logging. Once the decision-making group obtains information through collection and has a better understanding of the rainstorm water-logging, it will correct the probability of occurrence of rainstorm water-logging and the newly formed probability is called posterior probability. From the perspective of the probability theory, Bayesian reasoning is the problem of conditional probability reasoning.

In the above dynamic game model, the decision-making group should select the schemes of each stage. The key to the decision-making includes two aspects. One is the possible probability distribution 
of various states of rainstorm water-logging denoted by $P_{i}=\left(p_{1}, p_{2}, \ldots p_{n}\right)$ and the state transition probability matrix of water-logging, which is denoted as $p_{i j}$. The other is the payment function of the decision-making group.

As mentioned above, the decision-making group should have a prior belief on the probability of the state of rainstorm water-logging and the probability of the state transition. As the game process goes forward, the decision-making group should use the Bayes' rule to dynamically correct these prior beliefs.

Based on the posterior probability processing principle of Bayes' theorem, multi-stage emergency response schemes for rainstorm water-logging can be dynamically generated. It is assumed that the rainstorm water-logging are divided into $m$ stages and the possible states of water-logging events in each stage are represented by $\theta_{i}(i=1,2,3)$. When $i=1,2,3$, it means that the water-logging level is I, II, and III, respectively, or we say that the water-logging is in the first, second, and third states. The corresponding level of the emergency response plan is initiated when a certain level of water-logging occurs. Assuming that there are $k$ alternative sub-schemes in each level of the emergency plan, which are denoted by $a_{i k}$, then the decision should be made at each stage to choose a sub-scheme to be implemented from $a_{i k}$. In the sub-scheme set corresponding to the emergency plan of each level, there may be such a case that the corresponding sub-schemes of different levels are the same and the whole process is shown in Figure 4.

When making decisions on sub-schemes at each stage, the first step is to judge the state of the rainstorm water-logging, i.e., the level of rainstorm water-logging denoted by $\theta_{i}(i=1,2,3), \theta_{i} \in \psi$, where $\psi$ is the type space of the rainstorm water-logging disaster. Based on previous assumptions, we can get $\psi=\{\mathrm{I}, \mathrm{II}, \mathrm{III}\}$.

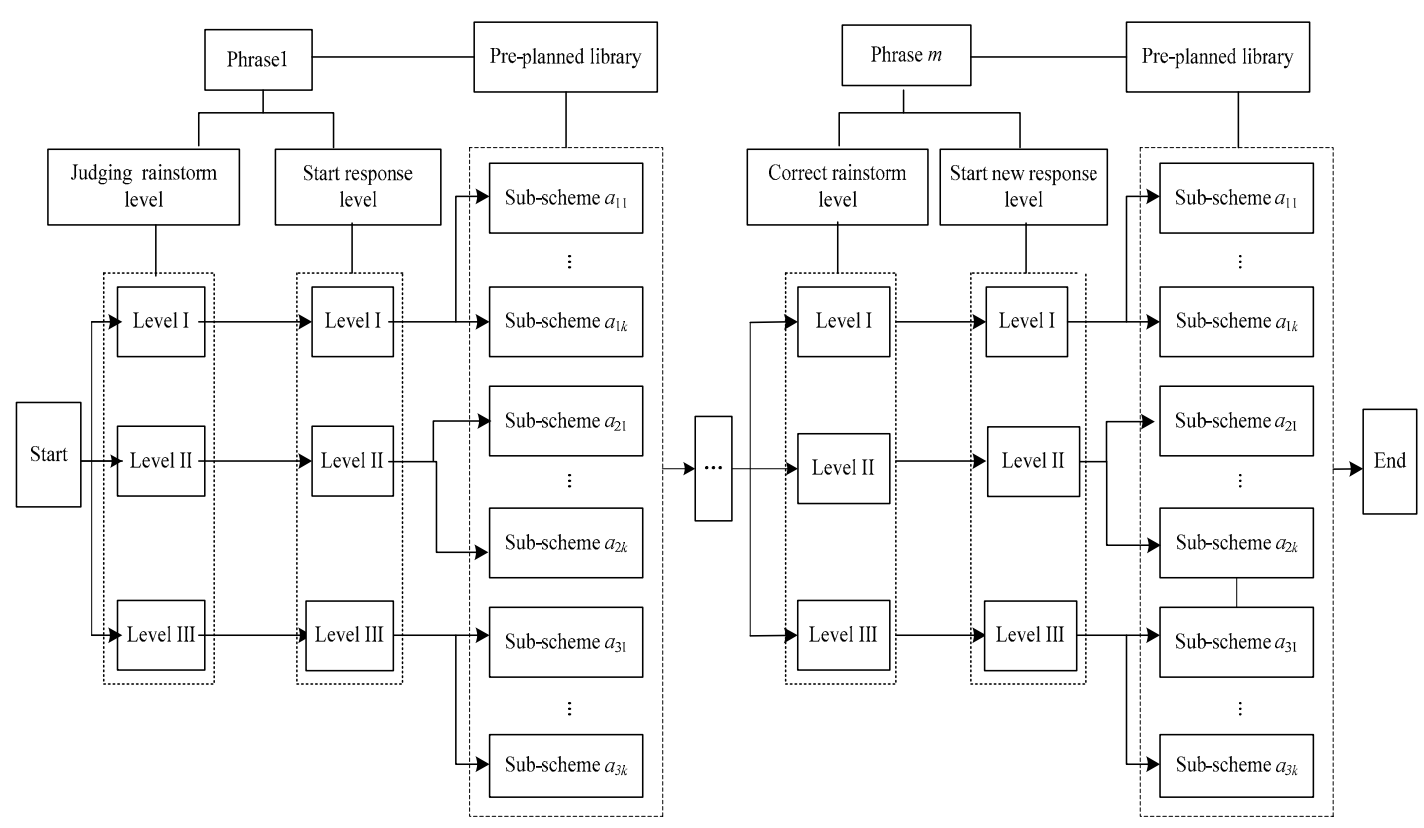

Figure 4. Dynamic generation process of emergency management schemes in water-logging.

The decision-making group does not know the specific type (level) $\theta_{i}$ of the rainstorm water-logging beforehand but knows that the prior probability of the water-logging at level $\theta_{i}$. Assume that the decision-making group judges that the prior probability is $p\left(\theta_{i}\right)(i=1,2,3)$ when the rainstorm water-logging is at the level $\theta_{i}$. Due to the lack of information for the decision-making groups, experts can be invited to correct the prior probabilities. For the sake of simplicity, the accuracy of an expert's prediction can be assumed based on historical conditions. Suppose that the probability of the following case is $p\left(\tau_{j} \mid \theta_{i}\right)$ : the expert's judgment for water-logging level is $\tau_{j}$ when the actual rainstorm water-logging level is $\theta_{i}$ and the accuracy of the expert's judgment is $p(j=i)$, which is the 
probability of the case that the expert's judgment $\tau_{j}$ is the same as the actual rainstorm water-logging level $\theta_{i}$. Using the Bayesian equation, the posterior probability of the rainstorm water-logging level $\theta_{i}$ can be obtained, which is the same as the probability denoted by $p\left(\theta_{i} \mid \tau_{j}\right)$ for the case that the expert's judge is $\tau_{j}$ while the actual level is $\theta_{i}$, and can be given by the equation below.

$$
p\left(\theta_{i} \mid \tau_{j}\right)=\frac{p\left(\tau_{j} \mid \theta_{i}\right) p\left(\theta_{i}\right)}{p\left(\tau_{j}\right)}=\frac{p\left(\tau_{j} \mid \theta_{i}\right) p\left(\theta_{i}\right)}{\sum_{i=1}^{3} p\left(\tau_{j} \mid \theta_{i}\right) p\left(\theta_{i}\right)}
$$

As for the payment function of the decision-making group in the emergency dynamic "game" of rainstorm water-logging, i.e., the determined utility level or the expected utility level obtained by the decision-making group, it can be represented by the utility function of the decision-making group. The utility function $u\left(\theta_{i m}, \tau_{j m}, a_{i m}\right)$ of the decision-making group is a function of the rainstorm water-logging level, the expert's judgment $\tau_{j}$, and the emergency decision-making scheme $a_{i}$ where $m$ is the $m$-th stage of the decision.

The utility function $u\left(\theta_{i m}, \tau_{j m}, a_{i m}\right)$ indicates that the utility level of scheme $a_{i m}$ in the $m$-th stage when the rainstorm water-logging level is $\theta_{i m}$ and the expert's judgment is $\tau_{i m}$. The goal of the decision-making group is to maximize the expected utility level. The function can be expressed by Equation (2) below.

$$
\operatorname{Max} U=\sum_{j=1}^{3} p\left(\theta_{i m} \mid \tau_{j m}\right) u\left(\theta_{i m}, \tau_{j m}, a_{i m}\right)
$$

where $p\left(\theta_{i m} \mid \tau_{j m}\right)$ is the posterior probability of rainstorm water-logging in the $m$-th stage at the level $\theta_{i}$, which can be solved according to the Bayes' rule (Equation (1)).

\subsection{Emergency Scheme Using Multi-Attribute Utility Theory}

\subsubsection{Utility Analysis of the Emergency Scheme}

With multi-attribute utility theory, each factor (attribute) is evaluated that plays a role in the decision-making process. Additionally, the solution with the best utility will be chosen by making comprehensive considerations.

The steps to make decisions using multi-attribute utility theory are below.

(1) Determine the attributes to be considered to solve the problem $X=\left\{x_{1}, x_{2}, \cdots, x_{n}\right\}$,

(2) Establish a utility function expression for each attribute $\mathrm{U}(X)$,

(3) Determine that the weight for each attribute $\omega_{j}, j=(1,2, \ldots, n) . \omega_{j}$ must satisfy Equation (3).

$$
\sum_{j=1}^{n} \omega_{j}=1
$$

At present, the methods for weight determination mainly include TOPSIS (Technique for Order Preference by Similarity to an Ideal Solution) [42], ELECTRE (ELimination Et Choix Traduisant la REalité) [43], DEMATEL (Decision Making Trial and Evaluation Laboratory) [44], and AHP (Analytic Hierarchy Process) [45]. In this study, it is not the research focus to determine the weight for each attribute. Thus, we do not discuss how to determine the weights in detail. As one kind of common methods, AHP can be used in this case. First, we design a questionnaire and select 10 to 15 experts in the field of water-logging emergency management to conduct a face-to-face interview with them. By using the expert data, we can get the weights of different attributes based on AHP.

(4) Identify alternatives $\mathrm{A}=\left(a_{1}, a_{2}, \ldots, a_{k}\right)$, 
(5) Calculate the utility of each scheme $U_{i}(X)$, which can be obtained by Equation (4).

$$
U_{i}(X)=\sum_{j=1}^{n} \omega_{j} u_{i}\left(x_{j}\right) i=1,2, \ldots, k
$$

In Equation (4), the utility value of scheme $i$ on the $j$-th attribute satisfies $0 \leq u_{i}\left(x_{j}\right) \leq 1$.

Determine the best solution according to the principle of utility maximization. Thus, the best solution satisfies Equation (5).

$$
U(X)=\max _{i}(X)=\max \sum_{j=1}^{n} \omega_{j} u_{i}\left(x_{j}\right) i=1,2, \ldots, k
$$

In the application of multi-attribute utility theory, a key issue is to determine the utility function of each attribute, which is a difficult issue to be addressed. For the sake of simplicity, this paper assumes that the value functions of various attributes involved in emergency management targets are all linear and all the value functions have an additive form. Thus, a simple additive weighting method can be used to make the decision and the value function of each attribute is approximately regarded as its utility function.

The simple additive weighting method is a method of the multi-objective value function method. Under the premise that the attribute set satisfies certain independence, the value function can be expressed as an additive form, as shown in Equation (6).

$$
V_{i}(X)=\omega_{1} v_{i 1}\left(x_{1}\right)+\omega_{2} v_{i 2}\left(x_{2}\right)+\ldots+\omega_{n} v_{i n}\left(x_{n}\right)=\sum_{j=1}^{n} \omega_{j} v_{i j}\left(x_{j}\right), i=1, \ldots, k
$$

In Equation (6), $V_{i}(X)$ and $V_{i j}\left(x_{j}\right)(i=1,2, \ldots, k)$ are both value functions where $v_{i j}$ represents the value function of the scheme $i$ on the $j$-th attribute and $v_{i}$ is the total value function of the scheme $i$. If the value function $v_{i}$ can be approximately seen as linear and the normalized attribute value $Z_{i j}$ is used as the value function of each attribute, i.e., $v_{i j}=Z_{i j}, i=1,2, \ldots, k$, then Equation (6) can be rewritten as the formula below.

$$
V_{i}(X)=\omega_{1} Z_{i 1}+\omega_{2} Z_{i 2}+\ldots+\omega_{n} Z_{i n}=\sum_{j=1}^{n} \omega_{j} Z_{i j}, i=1, \ldots, k
$$

In Equation (7), $Z_{i j}(i=1,2, \ldots, k ; j=1,2, \ldots, n)$ is the value after the $j$-th attribute of the scheme $i$, which is normalized.

For a cost-type attribute, it can be normalized using Equation (8).

$$
Z_{i j}=\frac{x_{j}^{\max }-x_{i j}}{x_{j}^{\max }-x_{j}^{\min }}
$$

For a benefit attribute, Equation (9) can be used for normalization.

$$
Z_{i j}=\frac{x_{i j}-x_{j}^{\min }}{x_{j}^{\max }-x_{j}^{\min }}
$$

In Equations (8) and (9), $x_{j}^{\max }=\max _{j} x_{i j} ; x_{j}^{\min }=\min _{j} x_{i j}$

Regarding the value function as a utility function approximately, we can get the equation below.

$$
U_{i}(X)=\sum_{j=1}^{n} \omega_{j} u_{i}\left(x_{j}\right)=\sum_{j=1}^{n} \omega_{j} Z_{i j}, i=1, \ldots, k
$$


By substituting Equation (10) into Equation (5), the best solution can be determined.

\subsubsection{Multi-Attribute Utility Evaluation of the Emergency Scheme}

\section{(1) Evaluation Attributes}

For emergency management of rainstorm water-logging, the goal should be to minimize the occurrence or reduce the impact and the losses caused by water-logging. The losses caused by water-logging generally include casualties, loss of property, and losses caused by traffic disruptions. Due to the contingency of casualties, controllable property losses, and the introduction of local emergency schemes, casualties and property losses are not considered in this article. In fact, when the water-loggings occur, the most affected urban transport network is relatively difficult to solve. Under the current conditions, effective emergency management measures can only be used to alleviate the impact of heavy rains on traffic. Thus, this paper mainly considers the impact of water-logging on traffic. The corresponding targets are to ensure smooth traffic operation and reduce emergency cost.

Based on the above analysis, three traffic parameters including vehicle average speed $V_{a}$, saturation $Q / Q_{c}$, and traffic density $R_{t}$ are established together with three emergency cost parameter indicators including labor $\operatorname{cost} C_{l}$, equipment rental $\operatorname{cost} C_{e}$, and material loss $\operatorname{cost} C_{m}$. These parameters constitute the evaluation attribute tree for emergency decision making of rainstorm water-logging, which is shown in Figure 5.

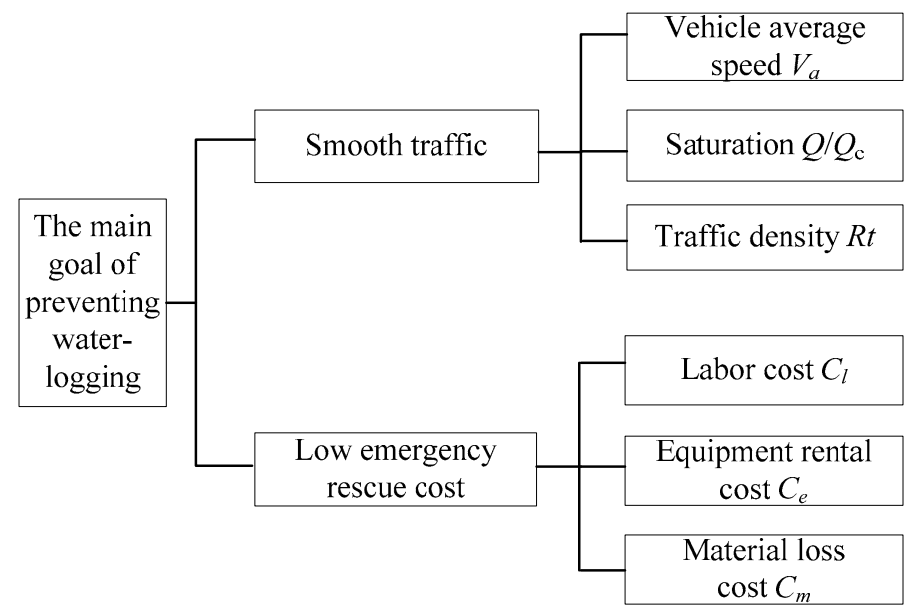

Figure 5. Evaluation attribute tree for water-logging emergency decision making.

(a). Average speed of vehicle flow $V_{a}(\mathrm{~km} / \mathrm{h})$. The average speed is usually referred to as the time average speed or the average point speed, which is the average of a set of instantaneous vehicle speeds measured at a given location on a road. It can be expressed by Equation (11) below.

$$
V_{a}=\frac{1}{M} \sum_{m=1}^{M} V_{m}
$$

In Equation (11), $V_{m}$ represents the vehicle speed $(\mathrm{km} / \mathrm{h})$ of the $m$-th car. $M$ is the total number of vehicles observed per unit time.

(b). Saturation. Saturation analysis is an important part of traffic control theory and an important indicator for evaluating road service levels. Road traffic saturation refers to the ratio of road traffic volume $Q(\mathrm{pcu} / \mathrm{h})$ to road design capacity $Q_{c}(\mathrm{pcu} / \mathrm{h})$. It reflects the actual load of the road. Among them, the traffic volume $Q$ refers to the actual number of vehicles passing through a certain location or a section of the road per unit time, which is also known as traffic flow.

(c). Traffic density $R_{t}$ (vehicles $/ \mathrm{km}$ ). Traffic density refers to the intensity of vehicles on a lane, i.e., the number of vehicles on a lane in a certain instantaneous unit length, which is also known as the 
traffic flow density (if there are multiple lanes, the number of vehicles are divided by the number of lanes into a single lane).

(d). Labor cost $C_{l}$, equipment rental $\operatorname{cost} C_{e}$, and material loss $\operatorname{cost} C_{m}$. They refer to the labor cost of the emergency scheme for rainstorm water-logging, the cost of renting equipment, and the cost of the flood prevention materials. Additionally, they constitute the total contingency cost of the scheme.

(2) Utility Functions, Attribute Values, and Attribute Weights

In order to use the additive weighting method for multi-attribute utility analysis, it is necessary to determine the maximum and minimum values of each attribute. Then, by normalizing, the value of each attribute is between 0 and 1 and the normalized attribute value is approximately regarded as a utility value. However, for the above six attributes, there is actually no absolute maximum or minimum value, so we can set an upper limit and a lower limit for the values of each attribute. For a benefit attribute, when the attribute value reaches or exceeds the upper limit, its normalized value is equal to or greater than 1 , but its utility value is regarded as 1 . In addition, when the attribute value is the minimum or lower than the minimum value, its normalized value is equal to or less than 0 , but its utility value is treated as 0 . For cost-type attributes, the opposite is true. The final utility values are all in the interval $[0,1]$.

For the three traffic parameter indicators including average speed, saturation, and traffic density of the vehicle combined with the international classification criteria and the specific conditions of Chinese cities, the upper and lower limits of the values of each attribute are determined, which is shown in Table 2.

Table 2. Upper and lower limits for the values of each attribute.

\begin{tabular}{ccc}
\hline Attribute Name & Upper Limit of Attribute Value & Lower Limit of Attribute Value \\
\hline Vehicle average speed $(\mathrm{km} / \mathrm{h})$ & 55 & 30 \\
Saturation & 1.0 & 0.6 \\
Traffic density $($ vehicles $/ \mathrm{km})$ & 42 & 11 \\
\hline
\end{tabular}

Taking the attribute value after standardization as the utility, the utility expressions of the above three attributes can be approximately given, respectively.

(a). Approximate utility expression of average speed can be given by the following equation.

$$
u_{i}\left(x_{j}\right)=\left\{\begin{array}{cc}
0, & x_{i j} \leq 30 \\
\left(x_{i j}-30\right) / 25, & 30<x_{i j}<55 \\
1 & x_{i j} \geq 55
\end{array}\right.
$$

(b). Approximate utility expression of saturation can be given by the formula below.

$$
u_{i}\left(x_{j}\right)=\left\{\begin{array}{cc}
0, & x_{i j} \geq 1.0 \\
\left(1.0-x_{i j}\right) / 0.4, & 0.6<x_{i j}<1.0 \\
1 & x_{i j} \leq 0.6
\end{array}\right.
$$

(c). Approximate utility expression of traffic density can be given by the equation below.

$$
u_{i}\left(x_{j}\right)=\left\{\begin{array}{cc}
0, & x_{i j} \geq 42 \\
\left(42-x_{i j}\right) / 31, & 11<x_{i j}<42 \\
1 & x_{i j} \leq 11
\end{array}\right.
$$

For the three indicators known as the labor cost, equipment rental cost, and material loss cost, it is necessary to determine their utility expressions after the relevant scheme is determined since the specific attribute value depends on the scheme itself. 
For each attribute weight, it can be discussed by experts among the expert group, which is why it is not discussed in detail here.

According to the above method, the utility function expressions of the six attributes in the attribute tree shown in Figure 4 are respectively determined and the weight of each attribute is determined by the expert. Then the total utility value of each scheme can be calculated accordingly.

\section{Example Analysis}

In this case, we have explored the methods described above (Sections 3.2-3.4) to evaluate the emergency management decision making in the water-logging case of Guangzhou city with hypothetical series of events.

At 4:30 a.m. in the morning, according to the forecast of the Meteorological Observatory, there would be a heavy rainstorm process in the downtown area of Guangzhou, China. The city flood control mobile rescue team was responsible for the emergency rescue of SCNU (South China Normal University) section of Zhongshan Avenue, which is one place apt to water-logging. After receiving the information, it would be on standby. At 5:50 a.m., there was continuous precipitation in the urban area. At 6:05 a.m., the weather station issued a Yellow Warning Signal.

It is assumed that the processing of the internal helium is divided into two stages. The schemes corresponding to the rainstorm water-logging in Class I of each stage are $a_{1}$ and $a_{2}$. The schemes corresponding to Class II are $a_{1}, a_{2}$, and $a_{3}$. The schemes corresponding to Class III are $a_{2}$ and $a_{3}$. The rescue forces of each scheme are shown in Table 3.

Table 3. Emergency forces of each scheme.

\begin{tabular}{cccc}
\hline Scheme & Small Rescue Group & Medium Rescue Group & Large Rescue Group \\
\hline$a_{1}$ & 7 groups & 4 groups & 1 group \\
$a_{2}$ & 6 groups & 3 groups & 1 group \\
$a_{3}$ & 5 groups & 2 groups & - \\
\hline
\end{tabular}

Among them, the labor cost, equipment rental cost, and material consumption cost of various types of emergency operation groups are shown in Table 4.

Table 4. Emergency cost of fifferent types of emergency rescue teams.

\begin{tabular}{cccc}
\hline Types of Emergency Cost & $\begin{array}{c}\text { Labor Cost } \\
\text { Emergency Rescue Team }\end{array}$ & $\begin{array}{c}\text { Equipment Rental Cost } \\
\text { (Thousand Dollar) }\end{array}$ & $\begin{array}{c}\text { Material Consumption } \\
\text { Cost (Thousand Dollar) }\end{array}$ \\
\hline Small group & 2 & 2 & 0.8 \\
Medium group & 4 & 3 & 1 \\
Large group & 10 & 8 & 2 \\
\hline
\end{tabular}

Assume that the maximum total emergency cost acceptable for Zhongshan Avenue is 100 (thousand dollar) of which the maximum labor cost is 100,000 dollars. The maximum equipment rental cost is 35,000 dollar and the maximum cost of materials is 15,000 dollar. According to the previous method and the scheme given in Table 5, the approximate utility expressions of labor cost, equipment rental cost, and material loss cost are given below.

Approximate utility expression for labor cost:

$$
u_{i}\left(x_{j}\right)=\left\{\begin{array}{cc}
0, & x_{i j} \geq 50 \\
\left(50-x_{i j}\right) / 38, & 12<x_{i j}<50 \\
1 & x_{i j} \leq 12
\end{array}\right.
$$


Approximate utility expression for equipment rental cost:

$$
u_{i}\left(x_{j}\right)=\left\{\begin{array}{cc}
0, & x_{i j} \geq 35 \\
\left(35-x_{i j}\right) / 28, & 7<x_{i j}<35 \\
1 & x_{i j} \leq 7
\end{array}\right.
$$

Approximate utility expression for material consumption cost:

$$
u_{i}\left(x_{j}\right)=\left\{\begin{array}{cc}
0, & x_{i j} \geq 15 \\
\left(15-x_{i j}\right) / 10, & 5<x_{i j}<15 \\
1 & x_{i j} \leq 5
\end{array}\right.
$$

(1) The first phase of the scheme selection.

Suppose that the decision making group judges that the prior probabilities of the three levels are as follows:

$$
p\left(\theta_{1}\right)=0.2, p\left(\theta_{2}\right)=0.5, p\left(\theta_{3}\right)=0.3
$$

We assume that the actual water-logging level is $\theta_{i}$, the expert's judgment is $\tau_{j}$, and the conditional probability value $p\left(\tau_{j} \mid \theta_{i}\right)$ is as shown in Table 5 .

Table 5. The First stage conditional probability.

\begin{tabular}{cccc}
\hline $\boldsymbol{p}\left(\boldsymbol{\tau}_{\boldsymbol{j}} \mid \boldsymbol{\theta}_{\boldsymbol{i}}\right)$ & $\boldsymbol{\theta}_{\mathbf{1}}$ & $\boldsymbol{\theta}_{\mathbf{2}}$ & $\boldsymbol{\theta}_{\mathbf{3}}$ \\
\hline$\tau_{1}$ & 0.4 & 0.3 & 0.3 \\
$\tau_{2}$ & 0.3 & 0.4 & 0.45 \\
$\tau_{3}$ & 0.3 & 0.3 & 0.25 \\
\hline
\end{tabular}

The Bayesian equation is used to calculate the posterior probability of the three states. According to Equation (1), the results are shown in Table 6. The calculation steps are shown below.

$$
\begin{aligned}
& p\left(\theta_{1} \mid \tau_{1}\right)=\frac{p\left(\tau_{1} \mid \theta_{1}\right) p\left(\theta_{1}\right)}{p\left(\tau_{1}\right)}=\frac{p\left(\tau_{1} \mid \theta_{1}\right) p\left(\theta_{1}\right)}{\sum_{i=1}^{3} p\left(\tau_{1} \mid \theta_{i}\right) p\left(\theta_{i}\right)}=\frac{0.4 \times 0.2}{0.4 \times 0.2+0.3 \times 0.5+0.3 \times 0.3}=0.25 \\
& p\left(\theta_{1} \mid \tau_{2}\right)=\frac{p\left(\tau_{2} \mid \theta_{1}\right) p\left(\theta_{1}\right)}{p\left(\tau_{2}\right)}=\frac{p\left(\tau_{2} \mid \theta_{1}\right) p\left(\theta_{1}\right)}{\sum_{i=1}^{3} p\left(\tau_{2} \mid \theta_{i}\right) p\left(\theta_{i}\right)}=\frac{0.3 \times 0.2}{0.3 \times 0.2+0.4 \times 0.5+0.45 \times 0.3}=0.15 \\
& p\left(\theta_{1} \mid \tau_{3}\right)=\frac{p\left(\tau_{3} \mid \theta_{1}\right) p\left(\theta_{1}\right)}{p\left(\tau_{3}\right)}=\frac{p\left(\tau_{3} \mid \theta_{1}\right) p\left(\theta_{1}\right)}{\sum_{i=1}^{3} p\left(\tau_{3} \mid \theta_{i}\right) p\left(\theta_{i}\right)}=\frac{0.3 \times 0.2}{0.3 \times 0.2+0.3 \times 0.5+0.25 \times 0.3}=0.21 \\
& p\left(\theta_{2} \mid \tau_{1}\right)=\frac{p\left(\tau_{1} \mid \theta_{2}\right) p\left(\theta_{2}\right)}{p\left(\tau_{1}\right)}=\frac{p\left(\tau_{1} \mid \theta_{2}\right) p\left(\theta_{2}\right)}{\sum_{i=1}^{3} p\left(\tau_{1} \mid \theta_{i}\right) p\left(\theta_{i}\right)}=\frac{0.3 \times 0.5}{0.4 \times 0.2+0.3 \times 0.5+0.3 \times 0.3}=0.47 \\
& p\left(\theta_{2} \mid \tau_{2}\right)=\frac{p\left(\tau_{2} \mid \theta_{2}\right) p\left(\theta_{2}\right)}{p\left(\tau_{2}\right)}=\frac{p\left(\tau_{2} \mid \theta_{2}\right) p\left(\theta_{2}\right)}{\sum_{i=1}^{3} p\left(\tau_{2} \mid \theta_{i}\right) p\left(\theta_{i}\right)}=\frac{0.4 \times 0.5}{0.3 \times 0.2+0.4 \times 0.5+0.45 \times 0.3}=0.51 \\
& p\left(\theta_{2} \mid \tau_{3}\right)=\frac{p\left(\tau_{3} \mid \theta_{2}\right) p\left(\theta_{2}\right)}{p\left(\tau_{3}\right)}=\frac{p\left(\tau_{3} \mid \theta_{2}\right) p\left(\theta_{2}\right)}{\sum_{i=1}^{3} p\left(\tau_{3} \mid \theta_{i}\right) p\left(\theta_{i}\right)}=\frac{0.3 \times 0.5}{0.3 \times 0.2+0.3 \times 0.5+0.25 \times 0.3}=0.53
\end{aligned}
$$




$$
\begin{aligned}
& p\left(\theta_{3} \mid \tau_{1}\right)=\frac{p\left(\tau_{1} \mid \theta_{3}\right) p\left(\theta_{3}\right)}{p\left(\tau_{1}\right)}=\frac{p\left(\tau_{1} \mid \theta_{3}\right) p\left(\theta_{3}\right)}{\sum_{i=1}^{3} p\left(\tau_{1} \mid \theta_{i}\right) p\left(\theta_{i}\right)}=\frac{0.3 \times 0.3}{0.4 \times 0.2+0.3 \times 0.5+0.3 \times 0.3}=0.28 \\
& p\left(\theta_{3} \mid \tau_{2}\right)=\frac{p\left(\tau_{2} \mid \theta_{3}\right) p\left(\theta_{3}\right)}{p\left(\tau_{2}\right)}=\frac{p\left(\tau_{2} \mid \theta_{3}\right) p\left(\theta_{3}\right)}{\sum_{i=1}^{3} p\left(\tau_{2} \mid \theta_{i}\right) p\left(\theta_{i}\right)}=\frac{0.45 \times 0.3}{0.3 \times 0.2+0.4 \times 0.5+0.45 \times 0.3}=0.34 \\
& p\left(\theta_{3} \mid \tau_{3}\right)=\frac{p\left(\tau_{3} \mid \theta_{3}\right) p\left(\theta_{3}\right)}{p\left(\tau_{3}\right)}=\frac{p\left(\tau_{3} \mid \theta_{3}\right) p\left(\theta_{3}\right)}{\sum_{i=1}^{3} p\left(\tau_{3} \mid \theta_{i}\right) p\left(\theta_{i}\right)}=\frac{0.25 \times 0.3}{0.3 \times 0.2+0.3 \times 0.5+0.25 \times 0.3}=0.26
\end{aligned}
$$

Table 6. Posterior probability of the first stage.

\begin{tabular}{cccc}
\hline$p\left(\boldsymbol{\theta}_{\boldsymbol{i}} \mid \boldsymbol{\tau}_{\boldsymbol{j}}\right)$ & $\boldsymbol{\tau}_{\mathbf{1}}$ & $\boldsymbol{\tau}_{\mathbf{2}}$ & $\boldsymbol{\tau}_{\mathbf{3}}$ \\
\hline$\theta_{1}$ & 0.25 & 0.15 & 0.21 \\
$\theta_{2}$ & 0.47 & 0.51 & 0.53 \\
$\theta_{3}$ & 0.28 & 0.34 & 0.26 \\
\hline
\end{tabular}

According to the information collected on the site and the weather forecast, the experts believe that the water-logging level is II and Table 6 shows that the posterior probability of the three levels is $0.15,0.51$, and 0.34 , respectively. As for the lack of specific data for the three indicators of traffic smoothness affected by different emergency rescue schemes under different water-logging levels, the assumptions are made in Table 7.

Table 7. Utility with traffic parameter indicators for optional sub-schemes.

\begin{tabular}{cccc}
\hline $\boldsymbol{U}\left(\boldsymbol{\theta}_{\boldsymbol{i}} \mid \boldsymbol{a}_{\boldsymbol{k}}\right)$ & $\boldsymbol{a}_{\mathbf{1}}$ & $\boldsymbol{a}_{\mathbf{2}}$ & $\boldsymbol{a}_{\mathbf{3}}$ \\
\hline$\theta_{1}$ & $(0.8,0.7,0.8)$ & $(0.2,0.3,0.2)$ & - \\
$\theta_{2}$ & $(0.2,0.2,0,4)$ & $(0.6,0.5 .0 .5)$ & $(0.2,0.1,0.1)$ \\
$\theta_{3}$ & - & $(0.3,0.2,0.2)$ & $(0.7,0.8,0.6)$ \\
\hline
\end{tabular}

The approximate utility of each program's labor cost, equipment rental cost, and material loss cost is calculated by Tables 3 and 4 and Equations (15)-(17). The calculation steps and results are shown in Table 8.

Table 8. Calculations of utilities with emergency cost parameter indicators for optional sub-schemes.

\begin{tabular}{ccccc}
\hline Utility & Scheme & a & $\mathbf{a}_{\mathbf{1}}$ & $\mathbf{a}_{\mathbf{3}}$ \\
\hline \multirow{2}{*}{ Labor } & Cost & $7 \times 2+4 \times 4+1 \times 10=40$ & $6 \times 2+3 \times 4+1 \times 10=34$ & $5 \times 2+2 \times 4=18$ \\
\cline { 2 - 5 } & Utility & $\frac{50-40}{38}=0.26$ & $\frac{35-34}{28}=0.04$ & $\frac{50-18}{38}=0.84$ \\
\hline \multirow{2}{*}{ Equipment rental } & Cost & $7 \times 2+4 \times 3+1 \times 8=34$ & $6 \times 2+3 \times 4+1 \times 10=34$ & $5 \times 2+2 \times 3=16$ \\
\cline { 2 - 5 } & Utility & $\frac{35-34}{28}=0.04$ & $\frac{35-29}{28}=0.21$ & $\frac{35-16}{28}=0.68$ \\
\hline $\begin{array}{c}\text { Material } \\
\text { consumption }\end{array}$ & Cost & $7 \times 0.8+4 \times 1+1 \times 2=11.6$ & $6 \times 0.8+3 \times 1+1 \times 2=$ & $5 \times 0.8+2 \times 1=6$ \\
\cline { 2 - 5 } & Utility & $\frac{15-11.6}{10}=0.34$ & $\frac{15-9.8}{10}=0.52$ & $\frac{15-6}{10}=0.9$ \\
\hline
\end{tabular}

We invited 15 experts to rate the importance of these six attributes including 10 experts from the Guangzhou Command Center for Flood, Drought and Typhoon Emergencies and 5 experts from universities or other research institutions. Assume that the weights of average speed, saturation, traffic density, labor cost, equipment rental cost, and material loss cost are $0.3,0.2,0.2,0.1,0.1$, and 0.1, respectively. Equations (10) and Equation (12)-(17) can be used to calculate the effects of 
implementing the corresponding schemes under different water-logging levels. This is shown in Table 9. The calculation steps are as follows.

$$
\begin{aligned}
& U\left(\theta_{1} \mid a_{1}\right)=0.3 \times 0.8+0.2 \times 0.7+0.2 \times 0.8+0.1 \times 0.26+0.1 \times 0.04+0.1 \times 0.34=0.60 \\
& U\left(\theta_{1} \mid a_{2}\right)=0.3 \times 0.2+0.2 \times 0.3+0.2 \times 0.2+0.1 \times 0.42+0.1 \times 0.21+0.1 \times 0.52=0.28 \\
& U\left(\theta_{2} \mid a_{1}\right)=0.3 \times 0.2+0.2 \times 0.2+0.2 \times 0.4+0.1 \times 0.26+0.1 \times 0.04+0.1 \times 0.34=0.24 \\
& U\left(\theta_{2} \mid a_{2}\right)=0.3 \times 0.6+0.2 \times 0.5+0.2 \times 0.5+0.1 \times 0.42+0.1 \times 0.21+0.1 \times 0.52=0.50 \\
& U\left(\theta_{2} \mid a_{3}\right)=0.3 \times 0.2+0.2 \times 0.1+0.2 \times 0.1+0.1 \times 0.84+0.1 \times 0.68+0.1 \times 0.9=0.34 \\
& U\left(\theta_{3} \mid a_{2}\right)=0.3 \times 0.3+0.2 \times 0.2+0.2 \times 0.2+0.1 \times 0.42+0.1 \times 0.21+0.1 \times 0.52=0.25 \\
& U\left(\theta_{3} \mid a_{3}\right)=0.3 \times 0.7+0.2 \times 0.8+0.2 \times 0.6+0.1 \times 0.84+0.1 \times 0.68+0.1 \times 0.9=0.73
\end{aligned}
$$

Table 9. Optional sub-scheme utility table.

\begin{tabular}{cccc}
\hline$U\left(\boldsymbol{\theta}_{\boldsymbol{i}} \mid \boldsymbol{a}_{\boldsymbol{k}}\right)$ & $\boldsymbol{a}_{\mathbf{1}}$ & $\boldsymbol{a}_{\mathbf{2}}$ & $\boldsymbol{a}_{\mathbf{3}}$ \\
\hline$\theta_{1}$ & 0.60 & 0.28 & - \\
$\theta_{2}$ & 0.24 & 0.50 & 0.34 \\
$\theta_{3}$ & - & 0.25 & 0.73 \\
\hline
\end{tabular}

According to Tables 6 and 9, the expected utility is calculated as follows.

$$
\begin{gathered}
E\left(U_{a_{2}}\right)=0.15 \times 0.28+0.51 \times 0.50+0.34 \times 0.25=0.38 \\
E\left(U_{a_{3}}\right)=0.51 \times 0.34+0.34 \times 0.73=0.42
\end{gathered}
$$

The expected utility of the first stage implementation schemes is $0.24,0.38$, and 0.42 , respectively. According to the principle of maximum expected utility, the decision-making group should choose scheme $a_{3}$ to be implemented in the first phase and consider the probability of the rainstorm water-logging level to initiate a Level III emergency response. Therefore, the Guangzhou Command Center for Flood, Drought and Typhoon Emergencies should start the emergency response to the water-logging at Level III and the city's flood headquarters will simultaneously initiate the emergency response of Level III. The municipal flood control mobile rescue team adopted the scheme $a_{3}$, according to the Level III emergency scheme, and used five small operation groups, and two medium-sized operation groupthat put emergency resources into rescue and immediately went to the SCNU section of Zhongshan Avenue. The team arrived at the site $30 \mathrm{~min}$ later.

(2) The second phase of scheme selection

As the rain continues, according to the importance of the road, the time, the flooding depth, and the weather forecast as well as whether there are other special circumstances, the on-site rescue management personnel should promptly exchange opinions with the city's flood headquarters.

According to the emergency rescue results of the first stage and after analyzing the new information collected, the decision-making group re-judges or corrects the level of water-logging. At this time, the probability of judging the level of rainstorm water-logging in the previous stage is the prior probability of this stage. That is:

$$
p\left(\theta_{1}\right)=0.15, p\left(\theta_{2}\right)=0.51, p\left(\theta_{3}\right)=0.34
$$

Assume that the value of the conditional probability $p\left(\tau_{j} \mid \theta_{i}\right)$ at this stage is shown in Table 10. 
The Bayesian equation is used to calculate the posterior probability of the three levels in the second stage. The calculation steps are as follows. In addition, the results are shown in Table 11.

$$
\begin{aligned}
& p\left(\theta_{1} \mid \tau_{1}\right)=\frac{p\left(\tau_{1} \mid \theta_{1}\right) p\left(\theta_{1}\right)}{p\left(\tau_{1}\right)}=\frac{p\left(\tau_{1} \mid \theta_{1}\right) p\left(\theta_{1}\right)}{\sum_{i=1}^{3} p\left(\tau_{1} \mid \theta_{i}\right) p\left(\theta_{i}\right)}=\frac{0.5 \times 0.15}{0.5 \times 0.15+0.25 \times 0.51+0.25 \times 0.34}=0.26 \\
& p\left(\theta_{1} \mid \tau_{2}\right)=\frac{p\left(\tau_{2} \mid \theta_{1}\right) p\left(\theta_{1}\right)}{p\left(\tau_{2}\right)}=\frac{p\left(\tau_{2} \mid \theta_{1}\right) p\left(\theta_{1}\right)}{\sum_{i=1}^{3} p\left(\tau_{2} \mid \theta_{i}\right) p\left(\theta_{i}\right)}=\frac{0.3 \times 0.15}{0.3 \times 0.15+0.5 \times 0.51+0.15 \times 0.34}=0.13 \\
& p\left(\theta_{1} \mid \tau_{3}\right)=\frac{p\left(\tau_{3} \mid \theta_{1}\right) p\left(\theta_{1}\right)}{p\left(\tau_{3}\right)}=\frac{p\left(\tau_{3} \mid \theta_{1}\right) p\left(\theta_{1}\right)}{\sum_{i=1}^{3} p\left(\tau_{3} \mid \theta_{i}\right) p\left(\theta_{i}\right)}=\frac{0.2 \times 0.15}{0.2 \times 0.15+0.25 \times 0.51+0.6 \times 0.34}=0.08 \\
& p\left(\theta_{2} \mid \tau_{1}\right)=\frac{p\left(\tau_{1} \mid \theta_{2}\right) p\left(\theta_{2}\right)}{p\left(\tau_{1}\right)}=\frac{p\left(\tau_{1} \mid \theta_{2}\right) p\left(\theta_{2}\right)}{\sum_{i=1}^{3} p\left(\tau_{1} \mid \theta_{i}\right) p\left(\theta_{i}\right)}=\frac{0.25 \times 0.51}{0.5 \times 0.15+0.25 \times 0.51+0.25 \times 0.34}=0.44 \\
& p\left(\theta_{2} \mid \tau_{2}\right)=\frac{p\left(\tau_{2} \mid \theta_{2}\right) p\left(\theta_{2}\right)}{p\left(\tau_{2}\right)}=\frac{p\left(\tau_{2} \mid \theta_{2}\right) p\left(\theta_{2}\right)}{\sum_{i=1}^{3} p\left(\tau_{2} \mid \theta_{i}\right) p\left(\theta_{i}\right)}=\frac{0.5 \times 0.51}{0.3 \times 0.15+0.5 \times 0.51+0.15 \times 0.34}=0.73 \\
& p\left(\theta_{2} \mid \tau_{3}\right)=\frac{p\left(\tau_{3} \mid \theta_{2}\right) p\left(\theta_{2}\right)}{p\left(\tau_{3}\right)}=\frac{p\left(\tau_{3} \mid \theta_{2}\right) p\left(\theta_{2}\right)}{\sum_{i=1}^{3} p\left(\tau_{3} \mid \theta_{i}\right) p\left(\theta_{i}\right)}=\frac{0.25 \times 0.51}{0.2 \times 0.15+0.25 \times 0.51+0.6 \times 0.34}=0.35 \\
& p\left(\theta_{3} \mid \tau_{1}\right)=\frac{p\left(\tau_{1} \mid \theta_{3}\right) p\left(\theta_{3}\right)}{p\left(\tau_{1}\right)}=\frac{p\left(\tau_{1} \mid \theta_{3}\right) p\left(\theta_{3}\right)}{\sum_{i=1}^{3} p\left(\tau_{1} \mid \theta_{i}\right) p\left(\theta_{i}\right)}=\frac{0.25 \times 0.34}{0.5 \times 0.15+0.25 \times 0.51+0.25 \times 0.34}=0.30 \\
& p\left(\theta_{3} \mid \tau_{2}\right)=\frac{p\left(\tau_{2} \mid \theta_{3}\right) p\left(\theta_{3}\right)}{p\left(\tau_{2}\right)}=\frac{p\left(\tau_{2} \mid \theta_{3}\right) p\left(\theta_{3}\right)}{\sum_{i=1}^{3} p\left(\tau_{2} \mid \theta_{i}\right) p\left(\theta_{i}\right)}=\frac{0.15 \times 0.34}{0.3 \times 0.15+0.5 \times 0.51+0.15 \times 0.34}=0.15 \\
& p\left(\theta_{3} \mid \tau_{3}\right)=\frac{p\left(\tau_{3} \mid \theta_{3}\right) p\left(\theta_{3}\right)}{p\left(\tau_{3}\right)}=\frac{p\left(\tau_{3} \mid \theta_{3}\right) p\left(\theta_{3}\right)}{\sum_{i=1}^{3} p\left(\tau_{3} \mid \theta_{i}\right) p\left(\theta_{i}\right)}=\frac{0.6 \times 0.34}{0.2 \times 0.15+0.25 \times 0.51+0.6 \times 0.34}=0.56
\end{aligned}
$$

According to the information collected on the site and the weather forecast, the experts believe that the water-logging state is at Level II. From Table 11, the posterior probability of the three levels is $0.13,0.73$, and 0.15 , respectively. According to Table 11 and scheme utility as shown in Table 9, the expected utilities of the second stage schemes are 0.35 and 0.51 . The calculation steps are as follows.

$$
\begin{gathered}
E\left(U_{a_{1}}\right)=0.13 \times 0.60+0.73 \times 0.24=0.25 \\
E\left(U_{a_{2}}\right)=0.13 \times 0.28+0.73 \times 0.50+0.15 \times 0.25=0.44 \\
E\left(U_{a_{3}}\right)=0.73 \times 0.34+0.15 \times 0.73=0.36
\end{gathered}
$$

According to the principle of maximum utility, we still choose option $a_{3}$ as the response scheme and propose to reduce the level of the emergency scheme in consideration of the probability of the water-logging level and the effect achieved in the first stage. Therefore, the new drainage emergency scheme formed by the second-stage decision-making group is to use 6 small operation groups, 3 medium-sized operation groups and 1 large operation group according to the level II emergency rescue. 
Table 10. The conditional probability.

\begin{tabular}{cccc}
\hline$p\left(\boldsymbol{\tau}_{\boldsymbol{j}} \mid \boldsymbol{\theta}_{\boldsymbol{i}}\right)$ & $\boldsymbol{\theta}_{\mathbf{1}}$ & $\boldsymbol{\theta}_{\mathbf{2}}$ & $\boldsymbol{\theta}_{\mathbf{3}}$ \\
\hline$\tau_{1}$ & 0.5 & 0.25 & 0.25 \\
$\tau_{2}$ & 0.3 & 0.5 & 0.15 \\
$\tau_{3}$ & 0.2 & 0.25 & 0.6 \\
\hline
\end{tabular}

Table 11. The posterior probability.

\begin{tabular}{cccc}
\hline$p\left(\boldsymbol{\theta}_{\boldsymbol{i}} \mid \boldsymbol{\tau}_{\boldsymbol{j}}\right)$ & $\boldsymbol{\tau}_{\mathbf{1}}$ & $\boldsymbol{\tau}_{\mathbf{2}}$ & $\boldsymbol{\tau}_{\mathbf{3}}$ \\
\hline$\theta_{1}$ & 0.26 & 0.13 & 0.08 \\
$\theta_{2}$ & 0.44 & 0.73 & 0.35 \\
$\theta_{3}$ & 0.39 & 0.15 & 0.56 \\
\hline
\end{tabular}

If the traditional method was adopted, it would not consider dividing the rainstorm water-logging into multiple stages. The water-logging level was Class III and the Level III response was activated. Additionally, the scheme $a_{3}$ selected in the first stage was used for the whole process.

The second state of water-logging in the second stage was Class II, but the traditional decision-making method still adopted scheme $a_{3}$ and the utility value was 0.36 . The newly proposed selected scheme $a_{3}$ and its utility value was 0.44 . In the above water-logging incident, the choice of the traditional method was less effective. The method proposed in this paper was more reasonable.

\section{Discussion}

This paper studied the emergency decision-making issue in water-logging through a comprehensive application of three major approaches. First, we constructed a process model for the emergency decision-making based on the dynamic network game technology. Then, the method for the dynamic generation of emergency schemes of different stages was put forward based on the Bayesian analysis. Lastly, the best scheme was selected by using the multi-attribute utility theory. An example showed that the proposed methods would be effective. However, some limitations also existed.

\subsection{Advantages of the Methods}

From the point of view of the evolving state of rainstorm water-logging, the emergency decision-making in water-logging is a dynamic system problem. Different from the traditional single-stage decision-making, this paper used dynamic game network technology to construct a multi-stage dynamic process model for emergency decision-making in rainstorm water-logging, which fully considered the phases and dynamic characteristics of the water-logging event in the decision process. Seen from the example, the multi-stage dynamic decision-making is better in line with the actual emergency decision-making in rainstorm water-logging, which makes the rescue forces and disaster relief materials to be reasonably arranged to reduce the losses. In addition, based on Bayesian analysis, the emergency schemes for each stage of heavy rain were further generated by using the historical emergency decision data of water-logging as well as future weather forecast information. In addition, this paper further analyzed the types of losses caused by rainstorm water-logging in the development perspective and determined the guarantee of traffic smoothness and emergency cost as the main objectives of emergency decision-making. On the one hand, it satisfied the ultimate goal of reducing water-logging losses and, on the other hand, it improved the efficiency of emergency decision-making. 


\subsection{Deficiencies and Prospects}

In the process of emergency decision-making during rainstorm water-logging, this paper supposed the "rainstorm water-logging" has "game" capabilities and established a dynamic game process between "rainstorm water-logging" and the "decision-making group" by considering the water-logging state evolution influenced by the measures taken in the previous stage by the "decision-making group." In fact, "rainstorm water-logging" does not have the subjective initiative like human beings. In addition, the "decision-making group" involves multiple departments in emergency decision-making such as the transportation department, fire department, and so on. Additionally, this paper did not focus on the impact of unclear responsibilities and linkages between departments related to emergency decision-making. For the evaluation attribute of the emergency scheme in the water-logging, this paper mainly considered two aspects, traffic smoothness, and emergency cost, which also had limitations. For the sake of simplicity, this paper used SAW and did not compare it with other multi-attribute decision making methods such as VIKOR (VlseKriterijumsKaOptimizacija I KompromisnoResenje) and MABAC (Multi-Attributive Border Approximation Area Comparison). This was also a limitation in the research process. In the future, these attributes and their weight determination methods should be considered more comprehensively. In the multi-attribute decision utility analysis, this paper did not discuss the weight of each attribute in detail. At the same time, it is necessary to study more practical utility functions with more practical data.

Emergency decision-making in rainstorm water-logging is a complex problem covering many aspects and many fields. It is difficult to express the emergency decision-making process of water-logging only by using the simple model. The method proposed in this paper is needed to verify through actual investigation. However, the research results of this paper have played a supporting role in the public understanding of the emergency decision-making process in rainstorm water-logging and also provided some reference significance for the emergency decision-making of relevant departments. In recent years, as people pay more attention to the rainstorm water-logging, it is necessary to formulate a more perfect emergency management model for rainstorm water-logging.

\section{Conclusions}

This paper focused on the issue of urban rainstorm water-logging and the research only dealt with the emergency decision-making of water-logging disasters caused by heavy rain in the urban area, which aims to improve the efficiency and accuracy of emergency management. In this paper, the dynamic game network technology was used to construct the process model for the emergency decision-making considering the dynamic characteristics of emergency management in rainstorm water-logging. Using the multi-attribute utility theory, the suitable scheme was determined from the aspects of traffic flow and emergency cost. The research methods were applied to a rainstorm water-logging process in Guangzhou to verify its validity. Compared the results with traditional decision-making methods, the newly proposed methods in this paper was more practical and targeted since it increased the efficiency of rescue forces by adopting different emergency schemes for the water-logging state of different stages. However, through further discussion, we found that the rationality of multi-attribute utility evaluation target selection needs to be further discussed, according to the losses caused by the water-logging in various cities. The determination of each attribute weight and the choice of a more appropriate multi-attribute decision-making method also needs to be discussed in detail in the future.

The rainstorm water-logging events and related data mentioned in this paper were mainly from Guangzhou. We hope it could provide certain reference value as well as enrichment and supplement for the emergency management department in cities in China or other countries in the world. Besides the emergency decision-making problem proposed in this paper, the emergency management research studies on rainstorm water-logging involves many other aspects and fields including the design of the emergency linkage organization system, the formulation of the emergency scheme, and the incentive 
mechanism design for emergency linkage. In order to better cope with urban rainstorm water-logging, the future research on emergency management can be discussed from the above aspects.

Author Contributions: J.D. conceptualized the work and designed the research framework. J.C. and J.D. completed the paper in English. G.G. participated in drafting the article and revised it critically for important intellectual content. C.C. revised the manuscript.

Funding: This research was funded by the Fundamental Research Funds for the Central Universities (Project No. 2017B18114) and the National Natural Science Foundation of China (Project No. 71402045)

Conflicts of Interest: The authors declare no conflicts of interest.

\section{References}

1. Li, C. Ecohydrology and good urban design for urban storm water-logging in Beijing, China. Ecohydrol. Hydrobiol. 2012, 12, 287-300. [CrossRef]

2. Yan, L. Data-Driven Simulation Method of Storm Flood Disaster Process; Wuhan University: Wuhan, China, 2017. (In Chinese)

3. Xue, F.; Huang, M.; Wang, W.; Zou, L. Numerical Simulation of Urban Water-logging Based on Flood Area Model. Adv. Meteorol. 2016, 1, 1-9. [CrossRef]

4. Pei, H.; Cao, S.; Wang, H. Urban Flood Risk Management and Disaster Compensation Research; China Water \& Hydropower Press: Beijing, China, 2008. (In Chinese)

5. Jia, H.; Yao, H.; Shaw, L. Advances in LID BMPs research and practice for urban runoff control in China. Environ. Sci. Eng. Front. 2013, 7, 709-720. [CrossRef]

6. China Daily. Sea Views in Cities. Available online: http://www.chinadaily.com.cn/opinion/2015-08/03/ content_21482992.htm (accessed on 5 August 2018).

7. Tang, X.; Shu, Y.; Lian, Y.; Hao, Y.; Fu, Y. A spatial assessment of urban water-logging risk based on a Weighted Naïve Bayes classifier. Sci. Total Environ. 2018, 630, 264-274. [CrossRef] [PubMed]

8. Zhang, D.; Wang, L. Research on Urban Emergency Management in Beijing Based on Complex System Theory. City 2016, 4, 49-53. (In Chinese)

9. Gao, Y.; Li, J. The Application of GIS Technology in the Cost Optimization Analysis of the Survey of Large-scale Water Conservancy Project. Eng. Econ. 2015, 4, 47-50. (In Chinese)

10. Jiang, R. Research on urban water-logging characteristics and response in changing environment. Chinese Meteorological Society. In Proceedings of the 33rd Annual Meeting of Chinese Meteorological Society S9 Hydrometeorological Disaster Forecasting and Early Warning, Xi'an, China, 2-5 November 2016. (In Chinese)

11. Yu, Z. Discussion on Urban Drainage Planning Management after Heavy Rainfall. Sci. Technol. Innov. 2015, 1, 49. (In Chinese)

12. Song, A. The Third Party Responsibility Risk Assessment Model and Insurance Research of Subway Civil Engineering Construction; Shenyang Aerospace University: Shenyang, China, 2017. (In Chinese)

13. Wang, Y.; Sun, M.; Song, B. Public perceptions of and willingness to pay for sponge city initiatives in China. Resour. Conserv. Recycl. 2017, 122, 11-20. [CrossRef]

14. He, X.; He, H.; He, Y. Impact Analysis of Urban Flood Disasters and Meteorological Services Countermeasures. Caizhi 2016, 35, 265. (In Chinese)

15. Yang, Y.; Feng, Z. Urban Population Density Based on Google Earth: A Case of Qingyuan City, Guangdong Province. Trop. Geogr. 2009, 6, 12.

16. Ding, Y. Research on Emergency Management of Natural Disasters in Guangzhou City-Taking Nie as an Example; South China University of Technology: Guangzhou, China, 2017. (In Chinese)

17. Ye, C.; Zhang, Y.; Cheng, W. Analysis of the status quo and causes of guilt in the process of rapid urbanization in Beijing. China National Defense. Drought Resist. 2018, 28, 19-25. (In Chinese)

18. Rodolfo, K.S.; Siringan, F.P. Global sea-level rise is recognised, but flooding from anthropogenic land subsidence is ignored around northern Manila Bay, Philippines. Disasters 2010, 30, 118-139. [CrossRef] [PubMed]

19. Wang, J.; Gao, W.; Xu, S.; Yu, L. Evaluation of the combined risk of sea level rise, land subsidence, and storm surges on the coastal areas of Shanghai, China. Clim. Chang. 2012, 115, 537-558. [CrossRef] 
20. Xu, Y. Strengthening the Design of Municipal Rainwater Pipe Network and Urban Relief Measures. City Archit. 2015, 17, 255.

21. Zhang, W.; Li, S.; Shi, Z. The causes of urban torrential rain and its coping strategies. J. Nat. Disasters 2012, 21, 180-184. (In Chinese)

22. Yin, J.; Xu, S.; Wen, J. Community-based scenario modelling and disaster risk assessment of urban rainstorm water-logging. J. Geogr. Sci. 2011, 21, 274-284. [CrossRef]

23. Yin, J.; Yin, Z.; Wang, J. GIS-based Risk Assessment of Urban Community Rainstorm Disaster. Geogr. Geo-Inf. Sci. 2009, 25, 92-95. (In Chinese)

24. Cai, Y.; Li, L.; Elahi, E.; Qiu, Y. Selection of Policies on Typhoon and Rainstorm Disasters in China: A Content Analysis Perspective. Sustainability 2018, 10, 387. [CrossRef]

25. Zhang, Z.; Wang, W.; Fang, D. Optimization Design of Wuhan Internal Monitoring and Early Warning System Based on Internet of Things and GPRS Technology. Saf. Environ. Eng. 2018, 25, 37-43. (In Chinese)

26. Jiang, R.; Wang, X.; Xie, J. Research and application of urban emergency planning management. Disaster Sci. 2018, 33, 146-150. (In Chinese)

27. Sun, C.; Zhong, S.; Deng, Y. Evaluation and decision-making optimization of Beijing emergency rescue plan based on the scenario of heavy rain disasters. Acta Geogr. Sin. 2017, 72, 804-816. (In Chinese)

28. Xie, J.; Qin, Y.; Meng, X.; Xu, J.; Wang, L. The fuzzy comprehensive evaluation of the highway emergency plan based on G1 method. In Proceedings of the IEEE International Conference on Computer Science and Information Technology, Chengdu, China, 9-11 July 2010.

29. Shi, W. Research on Several Issues in Emergency Plan Management; University of Science and Technology of China: Hefei, China, 2012.

30. Hoard, M.; Homer, J.; Manley, W.; Furbee, P.; Haque, A.; Helmkamp, J. Systems modeling in support of evidence-based disaster planning for rural areas. Int. J. Hyg. Environ. Health 2005, 208, 117. [CrossRef] [PubMed]

31. Yang, J.; Xu, C. Emergency Decision Engineering Model Based on Sequential Games. Syst. Eng. Procedia 2012, 5, 276-282. [CrossRef]

32. Wang, Y.; Wang, T.; Ye, X.; Zhu, J.; Lee, J. Using Social Media for Emergency Response and Urban Sustainability: A Case Study of the 2012 Beijing Rainstorm. Sustainability 2015, 8, 142-143. [CrossRef]

33. Yu, X.; Lu, Y.; Wang, X. Generation and dynamic adjustment of strong typhoon disaster emergency plan based on CBR and prospect theory. Fuzzy Syst. Math. 2017, 31, 182-190. (In Chinese)

34. Hansson, K.; Larsson, A.; Danielson, M.; Ekenberg, L. Coping with Complex Environmental and Societal Flood Risk Management Decisions: An Integrated Multi-criteria Framework. Sustainability 2011, 3, 1357-1380. [CrossRef]

35. Meng, F.; Wang, W.; Zhang, Y. Study on Evaluation Method of Investment Plan of Engineering Project Based on Generalized $\lambda$-Shapley Choquet Integral. Oper. Res. Manag. Sci. 2016, 25, 186-194. (In Chinese)

36. Zhang, H.; Du, Y.; Zhou, P. A Multi-attribute Decision Making Method Based on Incomplete Information and Its Military Application. Ship Sci. Technol. 2014, 36, 150-153. (In Chinese)

37. Luo, L.; Yang, B.; Li, H. Evaluation of industrial process control performance based on dynamic multi-attribute decision making method. J. Chem. Ind. Eng. 2018, 1-9. (In Chinese). Available online: http:/ / kns.cnki.net/kcms/detail/11.1946.TQ.20180605.1554.014.html (accessed on 26 September 2018).

38. Li, J.; Wang, D.; Liu, Z. The Location Method of Logistics Park Based on Hybrid Multi-attribute Decision-making under Low Carbon Perspective. J. Shenyang Univ. Nat. Sci. 2018, 30, 122-127. (In Chinese)

39. Chen, X.; Wang, Y. Multi-attribute Emergency Decision Method Considering Information Source Correlation. Syst. Eng. Theory Pract. 2018, 38, 2045-2056. (In Chinese)

40. Liu, Y.; Fan, Z.; Yuan, Y. Multiple Attributes Risk Decision Making Method for Emergency Response. Oper. Res. Manag. Sci. 2013, 22, 23-28. (In Chinese)

41. Hohai University. Emergency Response Mechanism Decision-Making Research Report in Guangzhou Command Center for Flood, Drought and Typhoon Emergencies; Hohai University: Nanjing, China, 2011.

42. Wang, Y.; Yan, C.; Lan, Y. Hesitant fuzzy TOPSIS multi-attribute decision making method based on prospect theory. Control Decis. 2017, 32, 864-870.

43. Milosavljević, M.; Bursac, M.; Tričković, G. The selection of the railroad container terminal in Serbia based on multi criteria decision making methods. Decis. Mak. Appl. Manag. Eng. 2018, 1. [CrossRef] 
44. Roy, J.; Adhikary, K.; Kar, S.; Pamucar, D. A rough strength relational DEMATEL model for analysing the key success factors of hospital service quality. Decis. Mak. Appl. Manag. Eng. 2018, 1, 121-142. [CrossRef]

45. Vasiljevic, M.; Fazlollahtabar, H.; Stevic, Z.; Veskovic, S. A rough multicriteria approach for evaluation of the supplier criteria in automotive industry. Decis. Mak. Appl. Manag. Eng. 2018, 1, 82-96. [CrossRef] 